\title{
Urgent surgery in a poorly controlled hyperthyroid patient
}

\author{
Hishani Imalka Perera ${ }^{1 *}$, Dharshini Selvapalan ${ }^{1}$, Anuja Abayadeera ${ }^{2}$ \\ Senior Registrar in Anaesthesiology ${ }^{\prime}$, National Hospital of Sri Lanka, Sri Lanka. Professor in \\ Anaesthesiology', Faculty of Medicine, University of Colombo, Sri Lanka.
}

\begin{abstract}
Hyperthyroidism is a multisystemic disease with its maineffects on the cardiovascular system. It is better to control thyroid hormone excess before surgery to avoid the risk of precipitating thyroid storm. This won't be practical in emergency or urgent surgeries. This is a case history of a 50 year old man with uncontrolled hyperthyroidism who underwent a gastrectomy for a carcinoma. Hyperthyroidism was managed with antithyroid drugs, beta blockers, glucocorticoids and magnesium sulphate.
\end{abstract}

\section{Case History}

50 year old male was admitted for laparoscopy assisted gastrectomy for a pyloric growth. He presented with dyspeptic symptoms, gastrooesophageal reflux, severe loss of appetite and loss of weight for 4 months duration. He later developed vomiting following meals. He was initially managed medically as gastro-oesophageal reflux disease. As he was resistant to medical therapy upper gastrointestinal endoscopy was performed, which revealed a pyloric growth causing partial gastric outflow obstruction.

He had hyperthyroidism but had defaulted treatment for last 10 years. He was clinically hyperthyroid. Free T4 was $5.55 \mathrm{ng} / \mathrm{dl}$ (normal range 0.9 to $2.4 \mathrm{ng} / \mathrm{dl}$ ) and $\mathrm{TSH}$ was $0.005 \mathrm{mIU} / \mathrm{L}$ (normal range $\quad 0.4-4.0 \mathrm{mIU} / \mathrm{L})$ which confirmed hyperthyroidism. He was started on carbimazole $15 \mathrm{mg}$ three times a day and propranolol 40mg twice a day and continued for 2 weeks. Despite the treatment he remained hyperthyroid. He had no other comorbidities. It was decided to go ahead with surgery as it was a malignancy and patient was very symptomatic with gastric outlet obstruction.

\footnotetext{
*Correspondence: Hishani Imalka Perera E mail: hlhimalka@gmail.com

https://orcid.org/0000-0002-4246-1054 Received: 24/01/2020

Accepted: 06/04/2020

DOI: http:/doi.org/10.4038/slja.v28i2.8536
}

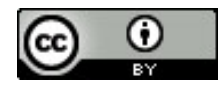

On the preoperative visit, he was anxious, BMI was $16 \mathrm{~kg} / \mathrm{m}^{2}$ and was mildly pale. There was a large multinodular goiter involving both lobes with mild tracheal deviation. His heart rate was 104 beats per minute and blood pressure, apex beat, and heart rhythms were normal. Other system examinations were normal.

On investigation, his haemoglobin was $10.8 \mathrm{~g} / \mathrm{dl}$. All the other investigations were within normal limits. ECG showed sinus tachycardia. Echocardiography was normal with preserved systolic and diastolic function.

Antiemetic, proton pump inhibitor and anxiolytics were prescribed as premedication. Antithyroid drugs and propranolol were continued in the perioperative period. Sleeping pulse were charted. Good rapport was made with the patient to allay his anxiety. Intravenous hydrocortisone $200 \mathrm{mg}$ was given 12 hours before the surgery.

On the day of the surgery standard monitoring was established with ECG with ST segment analysis, pulse oxymetry and noninvasive blood pressure. Core temperature was monitored with nasopharyngeal probe and peripheral temperature with axillary probe. Intravenous access was gained. He was tachycardic at the start and blood pressure was elevated (SBP 150mmHg). Intravenous hydrocortisone $200 \mathrm{mg}$ was administered first and was followed by $1.6 \mathrm{~g}$ of $\mathrm{MgSO}_{4}$ as a slow bolus. Modified rapid sequence induction was done with propofol, fentanyl and suxamethonium. Endotracheal intubation was done. Anaesthesia was maintained with isoflurane and morphine was given 
as the analgesic. Meticulous monitoring was carried out to detect the emergence of thyroid crisis with special attention to haemodynamics, capnography and temperature. Although we were ready with esmolol to be used in case of tachycardia patient's heart rate was within $70-80 / \mathrm{min}$ throughout the whole surgical period although the blood pressure was high. (SBP 140-160mmHg). Postoperative period was uncomplicated and antithyroid drugs were continued. Hydrocortisone was continued for 48 hours postoperatively.

\section{Discussion}

Effects of thyroid hormone excess on body are multisystemic. Devastating effects are to the heart causing atrial fibrillation, congestive cardiac failure, acute coronary syndromes and cardiomyopathies.

It is the norm that hyperthyroid patients should be euthyroid clinically and biochemically before undergoing surgery as it is a major identified precipitating factor for thyroid storm. Thyroid storm is an endocrine emergency with poor outcome and can cause severe cardiovascular instability and death. ${ }^{1}$ Stresses encountered in the perioperative period may exacerbate the thyroid disorder and precipitate crisis. But in the emergency and urgent settings there won't be an adequate time to control thyroid functions.

In our patient anti thyroid drugs were continued only for two weeks. It is necessary to have at least 6 weeks for antithyroid drugs to be effective. As our patient had a carcinoma and was symptomatic with gastric outlet obstruction, surgery was done with the uncontrolled hyperthyroidism.

Preoperative beta blockade is considered sufficient in patients with mild or subclinical hyperthyroidism. This is supported by a prospective randomized trial showing that in hyperthyroid patients who were treated with just 5 weeks of metoprolol preoperatively, there were no serious intra and postoperative complications,compared with patients with a combination of methimazole and levothyroxine to render them euthyroid. ${ }^{1}$ This is also helpful in patients who cannot be given antithyroid drugs, noncompliant patients and patients that are refractory to antithyroid drugs. ${ }^{2}$
Our patient was started on propranolol. Slight reduction of symptoms were noted with it but was still symptomatic as duration was not sufficient and as patient has had overt hyperthyroidism. Propranolol has the added advantage as it inhibits the monodeiodinase type 1 enzyme which converts $\mathrm{T} 4$ to the more biologically active $\mathrm{T} 3$ hormone.

Glucocorticoids have also been used in the treatment of hyperthyroidism and thyroid storm because they have an inhibitory effect on peripheral conversion of $\mathrm{T} 4$ to $\mathrm{T} 3$. $^{3} \mathrm{We}$ used hydrocortisone preoperatively, at the induction and postoperatively for 48 hours although the clinical relevance of this minor effect is unknown. ${ }^{3}$ But this effect seems to be occurring within a matter of hours thus beneficial in acute settings. ${ }^{1}$ Dexamethasone is another option.

Cholestyramine is another modality although we did not use it, for rapid reduction of thyroid hormone levels by binding thyroid hormone at the intestine and reducing its reabsorption. ${ }^{1}$

Invasive monitoring is indicated in uncontrolled hyperthyroid patients undergoing surgery to detect cardiovascular compromise. But we didn't use them as our patient was in sinus rhythm and echocardiogram was normal. We were ready with esmolol in case of tachycardia and atrial fibrillation, but it was not needed. There are case reports of successful management of patients with thyrotoxicosis for non-thyroid surgery with esmolol infusions. ${ }^{4}$

We used $\mathrm{MgSO}_{4}$ at the induction considering its membrane stabilizing effects, antiarrhythmic effect and negative inotropic effect. It worked well in this patient as heart rate was well controlled with $\mathrm{MgSO}_{4}$ throughout the intraoperative period. There were no case reports in the literature reporting the safe use of $\mathrm{MgSO}_{4}$ in perioperative period in uncontrolled hyperthyroid patients.

\section{References}

1. Palace MR. Perioperative Management of Thyroid Dysfunction. Health Serv Insights. 2017;10:117 https://doi.org/10.1177/1178632916689677 PMid:28469454 PMCid:PMC5398303 
2. Tay S, Khoo E, Tancharoen C, Lee I. Beta-blockers and the thyrotoxic patient for thyroid and non-thyroid surgery: A clinical review. OA Anaesthetics 2013;1(1):5.

https://doi.org/10.13172/2052-7853-1-1-491

3. Nayak B, Burman K, Thyrotoxicosis and thyroid strom, Endocrinology metabolism and clinics of North America. 2006:34;663-686

https://doi.org/10.1016/j.ecl.2006.09.008

PMid:17127140

4. Mehmet I, Sencan B, Anaesthetic management of a patient with thyrotoxicosis for nonthyroid surgery with peripheral nerve block, Hindawi Publishing Corporation Case Reports in Anesthesiology Volume 2016, Article ID 9824762.

https://doi.org/10.1155/2016/9824762

PMid:26885409 PMCid:PMC4738992 